\title{
La nueva creación en el pensamiento de Pablo
}

\author{
LUIS ESPÍNDOLA GARCÍA \\ Pontificia Universidad Javeriana (Colombia) \\ luis.espindola@javeriana.edu.co
}

\begin{abstract}
Resumen
En la tradición teológica de la religión judía que demostró poseer Pablo de Tarso, el Dios de Israel tiene el poder de crear y el poder de volver a crear; es decir, realizar una nueva creación. Pablo experimentó cómo en Jesús, Dios ha revelado la salvación, el perdón de los pecados por amor a toda la humanidad; y cada vez que un ser humano recibe este don por parte de Dios, se genera un nuevo ser. La comprensión e interpretación del mensaje teológico de Pablo sobre el tema de la nueva creación se basa en el discurso tomado en la carta de Pablo a los Gálatas $(6,11-16)$ y en las proposiciones escritas a los Corintios (2 Co 5,17$)$. Esta hermenéutica se complementa con la comprensión de otro discurso sobre el tema de la creación expuesto en la carta a los Romanos $(8,18$ 22).

Palabras clave: Nueva creación, hermenéutica bíblica, cartas de Pablo, salvación, Jesucristo.
\end{abstract}

\section{The new creation in Paul's thought}

\begin{abstract}
In the theological tradition of the Jewish religion that Paul of Tarsus proved to have, the God of Israel has the power to create and the power to re-create; that is, making a new creation. Paul experienced that in Jesus, God has revealed salvation, forgiveness of sins for the sake of all mankind, and every time which a human being receives this gift from God, a new being is created. The theological understanding and interpretation of Paul's message on the subject of the new creation is based on the speech made in his letter to the Galatians (6:11-16) and in one of his propositions in Corinthians (2 Co 5: 17). This hermeneutics is complemented from the understanding of another speech about the creation exposed in the Letter to the Romans (8: 18-22).
\end{abstract}

Keywords: New creation, biblical hermeneutics, letters of Paul, salvation, Jesus Christ.

Profesor e investigador de teología bíblica en la Facultad de Teología de la Pontificia Universidad Javeriana. Bachiller Eclesiástico, Licenciado y Magíster en Teología de la Pontificia Universidad Javeriana. Ha publicado el artículo "Aproximación teológica a 1Tes 1,1-10" (2011), y el capítulo en libro publicado con Alejandro Londoño: "Perspectiva a partir da Bíblia", en Murad Alfonso (Org), Ecoteologia: um mosaico (2016).

Recibido: 21/Junio/2016 - Aceptado: 27/Julio/2016 


\section{Introducción}

La reflexión teológica hoy, se concentra en los temas y problemas relacionados con la ecología: el abuso y la explotación por parte del ser humano de los recursos naturales que influyen en los desastres climáticos en el planeta. Para un creyente cristiano se trata de problemas relacionados con la Creación de Dios; pues, en la belleza y poder de la naturaleza se percibe la grandeza y maravilla de Dios. El tema de la Creación de Dios es un tema reconocido por la mayoría de creyentes cristianos, sin embargo, el tema de la nueva creación resulta más "especializado" y muchas veces desconocido, incluso para estudiosos de las cuestiones teológicas.

A partir de la profundización en tres textos canónicos, se quiere abordar estos dos conceptos fundamentales: creación y nueva creación y por supuesto, dar un poco más de tratamiento al tema de la nueva creación. En consecuencia, un objetivo evidente es presentar el fondo del pensamiento paulino respecto a los conceptos teológicos de creación y nueva creación y un objetivo abstracto es proponer a los lectores de este escrito; un punto de partida en la actual reflexión teológica sobre el cuidado de la casa común.

Los estudios específicos sobre los dos conceptos en Pablo, han estado arropados en artículos y escritos bajo el concepto bíblico de Creación. Las obras más cercanas al binomio: Nueva Creación, se explican y se funden desde la escatología teológica. Por esta razón, la bibliografía expuesta al final indica los tópicos por los cuales incursionó el autor para proponer esta integración temática. Desde el estudio de Pablo de Tarso y el Cristianismo Primitivo, hasta las obras de autores especialistas en exégesis de las cartas originales de Pablo como Senén Vidal.

Significa que la metodología seguida por el autor para alcanzar los objetivos, ha sido una hermenéutica de textos especializados. Los resultados de esta interpretación son los temas que a continuación se van a desarrollar. Inicialmente, se exponen las fuentes seguras y recomendables para un estudio serio que relacione el mensaje de Jesús de Nazaret y Pablo de Tarso. Después, una breve exposición sobre el autor de los conceptos: Pablo en calidad de Apóstol, implicado con el mensaje del Evangelio de Jesucristo. Después, los puntos centrales del artículo: la idea de nueva creación escrita en Gálatas 6,11-16; y 2 Corintios 5,17; finalmente, lo anterior relacionado con el concepto “creación” en Romanos 8,18-22. 


\section{Las fuentes que relacionan el mensaje de Jesús de Nazaret y Pablo de Tarso}

El tema de la nueva creación se inscribe dentro de la predicación y la teología de Pablo y las fuentes principales para descubrir este contenido son sus cartas (Gnilka, 1998: 19). Hoy se consideran auténticas, es decir, escritas por su propia mano o dictadas a un amanuense: la carta a los Romanos, las dos a los Corintios, a los Gálatas, a los Filipenses, la primera a los Tesalonicenses y la carta a Filemón. Estos escritos paulinos son fundamentales para el cristianismo, porque cronológicamente son los primeros escritos que se leen públicamente y hablan de Jesucristo; de hecho, la primera carta a los Tesalonicenses se fecha con precisión en el otoño del año 51 d.C.

En el mundo antiguo, las cartas fueron medios de comunicación entre grupos humanos y comunidades relacionadas por su cultura, lengua y tradición (Vouga, 2001: 17) sin embargo, Pablo las empleó para su actividad misionera, siguiendo modelos de cartas griegas y judías (Köster, 1988: 497).

La importancia de las cartas de Pablo está en su contenido teológico, son fuentes de primera mano de la historia y cronología de la configuración del cristianismo primitivo; por ejemplo, es un dato seguro e histórico la fecha de la actividad misionera de Pablo en Corinto entre la primavera del año 51 d.C. y la primavera del año 52 d.C. (Köster, 1988: 611).

También, el libro de los Hechos de los Apóstoles dedica más de la mitad de su contenido a relatar y exaltar la actividad misionera de Pablo en el periodo histórico de los años 30 d.C. a los años 60 d.C. Santiago Guijarro insiste en que "las informaciones de las cartas de Pablo son las más fiables desde el punto de vista histórico y el libro de los Hechos es la segunda fuente de información sobre este periodo" (Guijarro, 2011: 106). Junto a Guijarro, otros especialistas señalan que en la segunda obra de Lucas se insertan datos interesantes pero secundarios para reconfirmar los acontecimientos históricos.

Es claro que el problema de estas fuentes (incluidos los evangelios) para la investigación histórica no se puede dar en el ciento por ciento objetivamente pura, pues las tradiciones recogidas en estos documentos suponen ya una interpretación de hechos y acontecimientos históricos. Se puede hacer una "aproximación rigurosamente histórica" como ha sido el intento de Giuseppe Barbaglio, en su obra que trata el tema de la confrontación histórica entre Jesús de Nazaret y Pablo de Tarso (Barbaglio, 2009: 10, 42). Sin embargo, hay ventaja histórica con las fuentes paulinas, la mayoría de estudios así lo confirman: 
No existe otra figura de la primitiva comunidad que, aun permaneciendo en la penumbra de la historia, se nos presente con tanta claridad como la de Pablo. Incluso, respecto a la figura de Jesús, el historiador se encuentra en una situación más difícil que en el caso de Pablo, pues Jesús no dejó ningún documento escrito. Lo que sabemos de él se remonta a través de los evangelios hasta la tradición oral de la comunidad post-pascual y está tan profundamente identificado con el testimonio de fe, que relato histórico y expresión de fe de la primitiva cristiandad a menudo no pueden distinguirse con seguridad. Por esto, nuestro conocimiento del Jesús histórico es mucho más inseguro y fragmentario (Bornkamm, 1982: 13).

La lógica de la historia se interpreta en forma evolutiva; en primer lugar, relaciona los hechos y palabras del Jesús histórico; en segundo lugar, la actividad de la comunidad cristiana primitiva de Damasco; en tercer lugar, la actividad de la comunidad cristiana primitiva helenista de Antioquía, en cuarto lugar, la actividad misionera de Pablo de Tarso junto con las comunidades paulinas. Esta historia comprendió los primeros 60 años de la era cristiana. Esta secuencia se ha obtenido gracias a los documentos escritos de las cartas de Pablo y al libro de los Hechos de los Apóstoles.

\section{Pablo, Apóstol del Evangelio}

Saulo o Pablo de Tarso nació en una familia judía, motivo de orgullo para él (Flp 3, 5-8). Se deduce que los padres de Pablo eran pudientes, costearon el estudio de Pablo y promovieron el título de «Ciudadano Romano» (Hch 22, 25-28). Pablo contaba con parientes cercanos ubicados en puestos político-administrativos en las principales ciudades del imperio romano (Rm 16, 23; Hch 23, 16).

Aunque, inicialmente participó como perseguidor de los primeros cristianos en Damasco (Hch 9, 2; Ga 1,23) después, anunció hasta su muerte la Buena Nueva de la salvación. Pablo esperó la llegada del Mesías (elegido por Dios) para liberar a los pecadores del castigo de Dios en el fin de los tiempos (1 Ts 1,10), finalmente, experimentó en Jesús la plenitud de la salvación (la revelación de Dios) para él $(\mathrm{Ga} 1,12)$ y para los que creen en el Evangelio que él recibió (1 Co 15,2) pues, sólo la fe en Jesús justifica a los hombres judíos y paganos delante de Dios (Rm 1, 17$18 ; 3,21-31)$ y este es a su vez el fundamento y la importancia de creer en el "Dios vivo y verdadero" (1 Ts 1,9).

Pablo se convirtió en el hombre del Evangelio por excelencia; Dios lo puso aparte para el Evangelio (Rm 1,1), le reveló a su Hijo para que "lo anunciara entre los paganos" (Ga 1,15s) y le "confió el Evangelio" (1 Ts 2,4). Para Pablo, la proclamación del evangelio expresa el poder de Dios 
(Neirynck, 2004) y el sentido de identidad y pertenencia de los misioneros con Jesucristo; se trata de "nuestro evangelio" (1 Ts 1, 5a).

La presentación de Pablo como "Apóstol del Evangelio" en los saludos de sus Cartas es una lógica consecuencia de su pasado. Esta presentación es fundamental para legitimar su experiencia y el argumento de su teología; siempre ligado a sus vivencias vocacionales. "En suma: Pablo se presenta siempre ante sus comunidades como apóstol elegido por Dios" (Becker, 1996: 96). Después, en algunos textos, Pablo contó que en Damasco tuvo una experiencia con Jesús resucitado; se refiere a esto utilizando títulos cristológicos como «Señon», "Cristo" e "Hijo" (1 Co 9,1; 1 Co 15,8; Ga 1,16).

Pablo apoyó su relato vocacional en la tradición profética (Ga 1,5; ver Is 49,$1 ; \mathrm{Jr} 1,5)$ cuando afirma el haber sido elegido desde el seno materno. Esta fue una base sólida para fundamentar su vocación y su actividad misionera. "Sólo por la gracia", y el don del Espíritu, (1 Co 2,4) Pablo fue llamado al apostolado por Dios, este es el fundamento teológico de su autoridad con derecho de predicar, exhortar, enseñar, instruir, orientar y ser obedecido. (1 Co 15,1-11; 1 Tes 1,4.7). Esa gracia de Dios y ese don del Espíritu Santo otorgado a Pablo; junto con su "conversión intelectual" metanoia, sostenida con los cristianos de Damasco, y el haber escuchado la "doctrina cristológica" le llevó a adquirir una nueva comprensión de Dios (Becker, 1996: 101). Pablo fue consciente de su elección y vocación confiada por Dios para hacer el anuncio del Evangelio a los gentiles (1 Ts 2, 4) influido por la profunda impresión de Damasco.

El testimonio de Pablo sobre su conversión al Evangelio de Jesucristo, parte del anuncio sobre el origen divino de su apostolado. En palabras del mismo Pablo, la autoridad por la cual él cree en Jesús resucitado y por la cual practica su apostolado no tiene mediación humana (Ga 1,1b). La fuerza, el impulso de su conversión y su vocación apostólica estuvo relacionada con la resurrección de Jesús. El medio por el cual obtuvo la revelación del Evangelio, fue jla misma revelación divina! una revelación personal para comunicarle la salvación de Dios, es decir, fue una revelación de carácter soteriológica o de salvación de los pecados.

Desde entonces, hubo un cambio total en la vida del "Saulo" judío. Pablo fue consciente de esto, en algunos de sus escritos así lo manifestó; pero se nota especialmente la conciencia de su misma "fama" en su mensaje a los cristianos de Galacia: "El que antes nos perseguía ahora anuncia la buena nueva de la fe que entonces quería destruir" (Ga 1,23)". Sabugal Santos, concuerda en lo central de esta experiencia revolucionaria para Pablo que le llevó a cambiar radicalmente su dirección teológica; afirma que en Pablo su conversión se efectuó en sentido copernicano (Santos, 1976: 15). 
En este orden de ideas, se fundamenta la relación histórica entre Jesús de Nazaret y Pablo de Tarso. La actividad vital de Pablo de Tarso está íntimamente influenciada por el mensaje del Evangelio de Jesucristo, este fue su propósito central o su causa integral; con el anuncio y la escucha de la Buena Nueva de Jesús, Pablo experimentó su salvación. Ahora, resulta curioso e interesante saber cómo al tema de la redención o de la salvación realizada por Dios en Jesús; Pablo le asigna el binomio de "nueva creación".

Adicionalmente, sorprende que dos términos muy escasos en el vocabulario de Pablo tengan semejante relación de contenido teológico con términos como, justificación, salvación, santificación; palabras que abundan en sus escritos mientras que nueva creación o nueva criatura, solamente aparecen en dos de sus cartas y por relación temática en una tercera.

\section{La idea de nueva creación en Gálatas 6, 11-16}

Esta carta auténticamente paulina y unificada, se dirigió a las comunidades cristianas de la región de Galacia fundadas por Pablo (Hch 1314) y quienes fueron visitadas y cuestionadas por unos misioneros judaizantes opuestos a la doctrina de Pablo (Vidal, 1996: 71). Esta es la razón por la cual el tono de la carta es conflictivo. Pablo aprovecha para prevenir el peligro de la división y aclara que los cristianos gentiles sin circuncisión son legítimos o auténticos y que no necesitan primero ser "prosélitos" o judíos, ni practicar el rigor de la Ley.

En este contexto y de acuerdo con la estructura de esta carta, se comprende la parte final; como una conclusión de la misma:

¡Mirad con que letras tan grandes escribo esto de mi propio puño!: los que os fuerzan a circuncidaros sólo pretenden ser bien vistos por los demás, con el único fin de evitar la persecución por la cruz de Cristo. Pues ni siquiera esos mismos que se circuncidan cumplen la ley; sólo desean veros circuncidados para presumir de que lo habéis hecho gracias a ellos. En cuanto a mí, ¡Dios me libre de presumir si no es en la cruz de nuestro Señor Jesucristo, por la cual el mundo es para mí un crucificado y yo un crucificado para el mundo! Porque lo que cuenta no es la circuncisión ni la incircuncisión, sino ser una nueva criatura. Y para todos los que se sometan a esta regla, paz y misericordia, lo mismo que para el Israel de Dios (Ga $6,11-16)$.

En el mundo antiguo, era una costumbre común que al final de las cartas el autor realizara una conclusión para manifestar (probar) su au- 
tenticidad. Esta fue la razón de colocar la proposición: “... escribo esto de mi propio puño" (Ga 6,11). Y si también ha dicho antes: "con qué letras tan grandes"; lo hizo para aprovechar la conclusión y resaltar la importancia de lo que va a decir.

Aquí, Pablo confirma la polémica del contenido de esta Carta a los Gálatas con el objeto de enfatizar la salida o solución. Está diciendo que los opositores ni siquiera cumplen la ley por convicción sino por vano orgullo o por egoísmo (intereses), para salvarse de la persecución y de la marginación de una religión lícita (el judaísmo). Por esto, habla de los circuncidados que no cumplen la ley en recta intención. Contrario a ellos, Pablo afirma que él como creyente en el Señor Jesucristo se encuentra "crucificado para el mundo" (Ga 6,14) quiso decir: muerto por la ley, en la ley y con la ley; se pude decir, muerto al judaísmo.

Entonces, escribe la proposición conclusiva: "Porque lo que cuenta no es la circuncisión ni la incircuncisión, sino ser una nueva criatura" (Ga $6,15)$. Hay un carácter excluyente en este mensaje, se percibe una frase sintética y sonora; está diciendo que ni el judaísmo ni el paganismo es lo importante; lo fundamental es la conversión, la nueva forma de ser.

Puesto que la expresión: "...lo que cuenta no es la circuncisión ni la incircuncisión...” se encuentra también en Gálatas 5, 6 como: “...ni la circuncisión, ni la incircuncisión tienen eficacia sino la fe que actúa por la caridad" y en 1 Corintios 7,19 como: “...la circuncisión no es nada, y nada la incircuncisión; lo que importa es el cumplimiento de los mandatos de Dios", se deduce que fue un dicho generalizado, probablemente iniciado en la comunidad antioquena; quienes fueron conscientes de superar las diferencias entre judíos y gentiles y reconocer lo esencial o fundamental del cristianismo (Vidal, 1996: 107).

La crítica a la circuncisión está puesta como tema de fondo; ver los capítulos 2, 5 y 6 de la carta a los Gálatas; es una crítica que ya tenía su historia y desarrollo, pues la circuncisión implicaba para el judío cumplir un mandato fundamental de Dios (su Voluntad) y significaba la incorporación al judaísmo.

En Gálatas 2 se habla de la asamblea de Jerusalén y evidencia que un gentil no tiene por qué circuncidarse (v.3: "pues bien, ni siquiera Tito, que estaba conmigo, con ser griego, fue obligado a circuncidarse") por más que hubo "falsos hermanos que se infiltraron" (v.4) y se empeñaron en ello. Si los cristianos gálatas ya llevan un buen tiempo de haber "aceptado" la fe en el Evangelio, la preocupación de Pablo se enfoca en el comportamiento de ellos; pues no deberían ni dejarse convencer ni siquiera pensar en la justificación (salvación) con el cumplimiento de las leyes judías, esto significaría negar la gracia de Cristo y el don de la fe, 
sería validar la circuncisión a la cual Pablo consideraba de poca importancia.

Pablo comprendió que la elección de Dios, el cumplimiento de sus promesas de salvación se ha dado para todos, no solamente para judíos, sino también para los gentiles, comprendió que lo importante no es el cumplimiento de las obras de la ley sino la realización de las obras del Espíritu. Pablo reconoció que la sensibilidad de los gentiles a la acción y fuerza del Espíritu Santo, fue más efectiva en ellos que en los mismos judíos (1 Ts 1, 5).

Después del tema de la circuncisión, aparecen los términos griegos traducidos como: creación nueva; nueva creación y nueva criatura: en

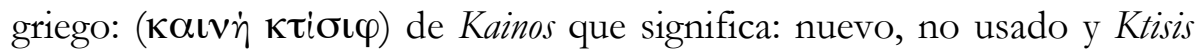
que significa: criatura, creación. Es la misma dirección significativa de Romanos 6, 4; vida nueva; y 7, 6; espíritu nuevo.

Pablo asumía naturalmente la acción creadora de Dios y la manifestación de Dios en sus criaturas (Rm 1, 20). Ya antes, en el inicio de esta carta a los Gálatas, Pablo había dicho: "Dios, que me había tomado aparte desde el vientre de mi madre y me había llamado con su gracia, decidió revelarme a su Hijo" (Ga 1, 15s). Esto comprueba que el pensamiento de Pablo tiene profunda relación con el pensamiento bíblico del Antiguo Testamento; tres tradiciones confirman este presupuesto histórico de esta concepción creadora de Dios: la tradición del Pentateuco, la tradición del pensamiento sapiencial y la tradición profética de Israel. De acuerdo con el Pentateuco, la concepción de Dios creador es evidente; y las tradiciones puestas en los dos primeros capítulos del libro del Génesis así lo confirman: "En el principio creó Dios el cielo y la tierra" (Gn 1,1); "Cuando Dios hizo la tierra y el cielo..." (Gn 2, 4). Además de ser el creador de los cielos y la tierra, en los orígenes, Dios creó al hombre y a la mujer y los constituyó administradores de la tierra (Auvray, 2001: 199).

Dentro de los escritos sapienciales el libro de Job insiste en la condición de criaturas no sólo el cosmos y sus elementos sino también y con especial interés el ser humano: "Escucha esto tranquilo, Job, piensa en los prodigios de Dios" (Job 37, 14). En este enfoque sapiencial, la actitud del ser humano ante Dios ha de ser de alabanza y reconocimiento; es así como los cantos de alabanza contienen la idea fundamental: todas las criaturas están abiertas hacia Dios. El poeta, quien compuso el Salmo 104 (103) tiene estrecha relación con la cosmogonía expuesta en Génesis 1. El salmista se inspiró en un himno egipcio al Dios Sol, compuesto por el año 1350 a.C., y su intención fue contemplar la maravilla de todo lo creado para reconocer y reconocerse también criatura ante el Creador (Rodríguez, 2009: 340). 
Para los profetas, Yahveh, Dios es el Creador del mundo, "Porque él es quien forma los montes y crea el viento..." (Am 4,13). Los profetas de Israel basaron su fe en Dios creador y dador de vida; los profetas de Israel invocaron a Dios en sus conflictos contra los seguidores de ídolos o dioses muertos. Paul Auvray recuerda algunos textos precisos en donde se evidencia la concepción de los profetas de Israel sobre los ídolos de los pueblos vecinos: "los ídolos son objetos sin vida, hechos de mano de hombre, incapaces de salvar: Jr 10, 1-5; Is 40,19s; 44, 9-20.” (2001: 196). Este pensamiento sobre Dios como Creador y fundamento de la vida estaba arraigado en la mente de Pablo cuando reconoció la conversión de los tesalonicenses, "y cómo os convertisteis a Dios, tras haber abandonado los ídolos para servir a Dios vivo y verdadero" (1 Ts 1, 9b).

Ahora bien, la importancia "exagerada" al concepto de nueva creación que Pablo afirmó en éste texto $(\mathrm{Ga} 6,15)$ se enfoca en la experiencia de salvación o redención manifestada a él (como judío) y a los demás paganos con el poder del Espíritu Santo; Pablo reconoce una fuerza espiritual, original y fundante que transforma las "seguridades humanas" (Santamaría, 2012: 236). Pudo ser la comodidad y aparente "seguridad" en que muchos judíos recordaban la Antigua Alianza y por esto, Pablo se enfoca en la Nueva Alianza, en la misma tradición y línea del profeta Jeremías y el profeta Ezequiel (Sánchez, 2007: 286).

La fuerza con el poder para renovar y "cambiar" la creación o las criaturas, especialmente el ser humano, quien se ha instalado en su vida y en su forma de pensar; ha de coincidir con el mismo plan de Dios y la manera de revelarse. Pablo experimentó esa fuerza en el amor y en el perdón de Dios hacia él. Esta es la novedad del Evangelio revelada de manera personal y para todos; así lo ha comprendido Jordi Sánchez Bosch: "El principio fundamental de que "no hay [distinción entre] judío y no judío, esclavo y libre, varón y mujer" (Ga 3, 28) no se apoya, como en principio hubiera podido hacer, en la creación, sino en la redención ("En Cristo Jesús, todos sois uno"). Pero esa redención recibe, también en esta carta (Ga 6, 15) el nombre de "nueva creación” (Sánchez, 2007: 52). Para Pablo el amor de Dios en Jesucristo es universal y es el auténtico poder transformador-creador.

A partir de la fe en el Evangelio de salvación, la paz y la misericordia son las características de la vida de los cristianos, afectados positivamente por el poder de la revelación de $\operatorname{Dios}(\mathrm{Ga} 6,16)$.

\section{La idea de "nueva creación" en 2 Corintios 5, 17}

El fundamento teológico del pensamiento paulino que busca orientar a la comunidad de Corinto no se distancia del pensamiento que en- 
frentó a la comunidad pagano-cristiana de Galacia. En este segundo texto de estudio, Pablo utilizó los mismos términos que en Gálatas 6, 15.

Lo digo porque el que está en Cristo es una nueva creación; pasó lo viejo, todo es nuevo. (2 Co 5, 17).

Aparecen dos puntos que enmarcan los términos nueva creación: "en Cristo", y "pasó lo viejo, todo es nuevo" ¿Qué significa la expresión

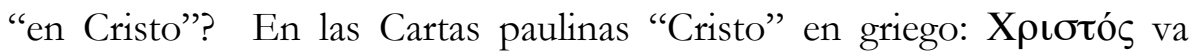
acompañado 46 veces del nombre de Jesús: 18 siguiéndole ("Jesús Cristo") y 28 procediéndole (“Cristo Jesús"); entre estas últimas, 17 veces forman el sintagma "en Cristo Jesús". Además, el nombre de Jesús, "Cristo" va acompañado 28 veces del título de Señor. "Cristo" más que cognomen de Jesús, casi pasa a ser simplemente su nombre (Sánchez, 2007: 169).

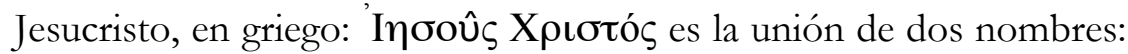
Jesús y Cristo. Este nombre compuesto lingüísticamente, tiene correspondencia histórica con los escritos del Nuevo Testamento en donde aparece con abundancia. Pablo algunas veces prefiere llamarlo

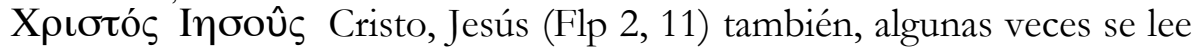
«el Mesías Jesús», todo esto para dar a entender la confesión primaria de fe: Jesús es el Cristo o el Cristo es Jesús; donde Cristo es igual a Mesías o Ungido. Pablo, ante los filipenses, confiesa la plenitud de su fe en el juicio que hace de Jesús Cristo: "Juzgo que todo es pérdida ante la sublimidad del conocimiento de Cristo Jesús, mi Señor, por quien perdí todas las cosas y las tengo por basura para ganar a Cristo" (Flp 3,8). En los escritos de Pablo el nombre compuesto de Jesucristo está al comienzo o al final de las secciones más importantes de sus Cartas.

Unido a las ideas anteriores; Pablo dice que quien está en Cristo ha experimentado el amor y el perdón de Dios por el poder del Espíritu Santo. Sobre la preposición en $(\varepsilon v)$ y sus diversos significados, se puede concluir que tiene sentido locativo (en el lugar del templo) y sentido de pertenencia (en unión con los ídolos). Esta discusión ha llevado a tener varias perspectivas en la correcta interpretación de los textos en donde aparece la expresión "en Cristo".

Tal vez hoy, las tres posturas más importantes sobre la interpretación de la expresión "en Cristo" han sido expuestas por J. Gnilka (1998: 103-105); la primera, subraya el sentido espacial de la interpretación: se existe "en Cristo" como fundidos en su Ser, en sentido místico o espiritual; la segunda, pone el acento en el sentido modal, es decir, la forma como muere y resucita Jesús condiciona y afecta su atracción y pertenencia y la tercera, en sentido eclesial o comunitario, pues la exaltación gloriosa de Cristo o del Señor realizada por Dios continua obrando o ac- 
tuando en la Comunidad de los bautizados. Las tres posturas son válidas y han tenido respuesta en diferentes corrientes cristianas.

Por tanto, el significado de: "el que está en Cristo" es profundamente teológico para recordar la comunión básica de los cristianos corintios en la persona de Jesús glorificado. El creyente está unido a Cristo. Esta comunión afecta y abarca todas las dimensiones de la vida.

"El que está en Cristo es una nueva creación". Para llegar a esta exclamación, Pablo venía argumentando una experiencia personal de salvación. En este texto discursivo, Pablo habla de lo esencial, de lo interno, de aquello que sólo se ve desde una experiencia salvífica y que parece una locura exterior ("perder el juicio por Dios").

Pablo afirma haber experimentado el amor de Cristo a partir de su muerte en cruz; Él murió por todos y el motivo de su muerte reunió (y reúne) a quienes creen en Él. Por esto, los que viven ya no vivan para sí sino para estar en Cristo. El misterio del amor de Dios en Cristo, dice Pablo, sobrepasa los criterios de los juicios humanos (2 Co 5, 18).

¿Qué entiende Pablo o qué quiere decir con la expresión "pasó lo viejo todo es nuevo"? Significa el reconocimiento del cumplimiento de las promesas de Dios (en Cristo) hechas por los profetas; posiblemente, Pablo evoca la tradición de Isaías 65, 17: "voy a crear unos cielos nuevos junto con una tierra nueva". La encarnación de Cristo es la novedad de Dios; con esta expresión hay coherencia interna en Pablo, quien reconoce que los "valores" del mundo antiguo ya están devaluados. Se abre una nueva manera de asumir la existencia.

Es una existencia con un "hombre nuevo" creado en Cristo, para una vida nueva, de justicia y santidad. Esta nueva forma de vida o existencia cristiana afecta a todo el universo; primero a las personas y después a la naturaleza y a las cosas. Pablo reconoce que el fundamento de esta nueva creación es la reconciliación. En este sentido; Pablo termina las ideas expuestas cuando exhorta, insiste y pide, como si Dios lo hiciera por medio de él y de los apóstoles: “ireconciliaos con Dios!” (2 Co 5, 20).

Ha desaparecido lo viejo, las viejas divisiones la enemistad entre los hombres y Dios; ahora es el tiempo de la reconciliación, Pablo, piensa en el cambio radical que ha tenido en Damasco y a partir de la interpretación de sus tradiciones, reconoce que la reconciliación también está brindada por parte de Dios para el mundo que es su creación maravillosa.

Acontece en Pablo una comprensión integral: Dios siempre ha estado fiel a su naturaleza a su Palabra, la prueba es Cristo; así también lo comprende Gustavo Baena S.J., cuando comenta el final de este mismo texto $(2 \operatorname{Co} 5,19)$ : 
Si, pues, "Dios estaba en Cristo" o acontecía personalmente en Cristo, lo que allí estaba Dios haciendo era justamente estando, esto es, reconciliando al mundo consigo y por el poder mismo de Dios creador; porque si Dios crea el mundo, y especialmente al hombre estando en él, o aconteciendo en él, o autocomunicándose en él, este ya tiene en sí una tendencia trascendental original, gratuitamente dada, de volverse de su limitada criaturidad hacia el infinito, hacia su creador, de donde procede, porque "todo proviene de Dios" (v.18) si el hombre la acoge desde el libre ejercicio de su existencia (Baena, 2011: 714).

Dos condiciones se imponen por parte del ser humano: la sensibilidad a la contemplación de todas las formas de existencia como creación de Dios y la "libertad" entre comillas para reconocer esta verdad (Rahner, 2008: 48).

\section{El concepto de “creación” en Romanos 8, 18-22}

La carta de Pablo a los Romanos, es como el testamento teológico de Pablo en donde resume gran parte de su reflexión e interpretación de la tradición religiosa judía. El motivo central de toda la carta a los Romanos es el pensamiento paulino sobre su interpretación de la Revelación que está en conformidad con las "Escrituras divinas". En las Sagradas Escrituras judías, estaba testificada la voz profética de las Promesas de Dios; de acuerdo con el contenido de la carta a los Romanos, esas Promesas se cumplen en el Evangelio de Jesucristo.

En el origen del pensamiento reformista, Martín Lutero estudió los escritos paulinos pero la carta a los Romanos suscitó en él profunda admiración: "Esta carta es la verdadera parte principal del Nuevo Testamento y el Evangelio más puro. Es digna de que todo cristiano, no solo la sepa de memoria palabra por palabra, sino también de que se ocupe en ella como su pan cotidiano del alma" (Lutero, 2003: 11). De acuerdo con Lutero, Pablo comprendió de manera integral el mensaje espiritual de Jesucristo y así lo quiso transmitir en la Carta a los Romanos.

Estudiar el texto de: Romanos 8, 18-22, ayuda a la comprensión del tema anterior de la reconciliación, pues el carácter negativo que contrasta con la exposición del concepto "creación" así lo evidencia (Santamaría, 2012: 239). Aunque sólo aparece el término “creación”, se percibe el seguimiento conceptual con el tema de la nueva creación.

Soy consciente de que los sufrimientos del tiempo presente no se pueden comparar con la gloria que se ha de manifestar en nosotros. Incluso la creación espera ansiosa y desea vivamente el momento en que se revele nuestra condición de hijos de Dios. La creación, en efecto, fue sometida a 
la caducidad, no espontáneamente, sino por voluntad de aquel que la sometió; pero latía en ella la esperanza de verse liberada de la esclavitud de la corrupción para participar en la gloriosa libertad de los hijos de Dios. Pues sabemos que la creación entera viene gimiendo hasta el presente y sufriendo dolores de parto ( $\operatorname{Rm~8,18-22).~}$

En el discurso sobre la vida del creyente cristiano por el poder del Espíritu, Pablo continúa con el tema del sufrimiento contrastado con la esperanza futura de la felicidad y gloria. Pues al final de estas ideas en Romanos 8, 35 dice: ¿Quién nos separará del amor de Cristo? ¿La tribulación?, ¿la angustia?, ¿la persecución?, ¿'el hambre?, ¿la desnudez?, ¿los peligros?, ¿la espada? Con estas preguntas Pablo quiere decir que el sufrimiento del cristiano se relativiza.

Antes, expuso un discurso sobre el cuerpo y el Espíritu (Rm 7, ss) de cómo el cuerpo lleva a las obras de la carne opuestas a las obras del Espíritu; las tendencias de la carne son muerte y llevan al odio a Dios; esto causa sufrimiento, pero hay esperanza en la lucha entre la carne, el cuerpo y el Espíritu. Después, vendrá la Gloria, se espera también el rescate del cuerpo $(\mathrm{Rm} 8,23 \mathrm{c})$ todo esto por el amor de Dios $(\mathrm{Rm} 8,39)$.

Después, retoma en su discurso nuevamente el tema del sufrimiento ( $\mathrm{Rm}$ 9, 1ss) pero en sí mismo, habla del dolor en su corazón: "siento una gran tristeza y un dolor incesante en el corazón" (Rm 9, 2). El motivo del dolor para Pablo fue comprender y constatar que los gentiles, quienes no buscaban la justicia han hallado la justificación: la justicia de la fe, mientras Israel, buscando una ley de justicia, no llegó a cumplir la ley. Esto causó profunda tristeza en Pablo quien la reconoció.

Es posible imaginar que Pablo tuvo que doblegar su pensamiento y reconocer ante el Misterio de Dios la causa de su mismo dolor escribiendo esto. ¿Por qué? porque comprueba la realidad de incredulidad de muchos judíos quienes buscan su felicidad y realización no en la fe, sino en sus obras, esto es: tropiezan también contra la piedra de tropiezo (1 Pe 2,7-8).

Este marco se repite en todo el v. 18: "soy consciente de que los sufrimientos del tiempo presente no se pueden comparar con la gloria que se ha de manifestar en nosotros". Aparece el tema de la creación en v. 19: "Incluso la creación espera ansiosa y desea vivamente el momento en que se revele nuestra condición de hijos de Dios". La mentalidad judía en su mayoría tenía presente que la tierra, el suelo había sido maldecido por parte Dios a causa de la desobediencia a sus leyes: "Al hombre le dijo: 'Por haber escuchado la voz de tu mujer y comido del árbol del que yo te había prohibido comer, maldito sea el suelo por tu causa: con fatiga sacarás de él el alimento todos los días de tu vida"' (Gn 3, 17). En este relato 
de la creación del mundo y el ser humano, seguido del relato de la caída, Dios maldice (condena) a la serpiente y a la tierra (suelo). Los seres humanos se ven afectados por el orgullo y la desobediencia a Dios; la mujer como madre y esposa y el hombre como trabajador, labrador del suelo o de la tierra.

La creación se halla en estado de caducidad, vanidad, corrupción, destrucción, sufrimiento, gemidos. Es una imagen negativa en el pensamiento bíblico, pero la causa de todo este estado de cosas fue la maldad del hombre: "Por eso, la tierra está en duelo, y se marchita cuanto en ella habita, con las bestias del campo y las aves del cielo, y hasta los peces del mar desaparecen" (Os 4,3). Pablo señala que la causa del estado violento de la creación se dio "por voluntad de aquel que la sometió" (v. 20) se refiere a Adán. Aunque algunos han interpretado que se refiere a Dios, tal vez por la tradición de Gn 6,7; en la que Dios anuncia exterminar al ser humano que había creado (Vidal, 1996: 432).

A pesar de la situación de pecado en la que no hay ni fidelidad, ni amor, ni conocimiento de Dios; y en donde solo reinaban las mentiras, los asesinatos, los robos y la violencia; ya el profeta Oseas había colocado el tema de la esperanza latente $(\mathrm{Os} \mathrm{4,2).} \mathrm{El} \mathrm{profeta} \mathrm{describió} \mathrm{la} \mathrm{situa-}$ ción actual de su pueblo contraria a la situación ideal que sería la del pueblo renovado: ¡la armonía entre el hombre y la creación!: (Os 2, 20 25).

Pablo comprendió que la promesa de Dios se cumplió en Cristo. Pablo ya está experimentando la gloriosa libertad de los justificados ante Dios. La tradición judía con enfoque apocalíptico espera la inminente llegada del día del Señor, en que se manifestaba la ira de Dios (contra los injustificados). Era una tradición fundamentada en la esperanza: "esperando y acelerando la venida del Día de Dios, en el que los cielos, en llamas se disolverán, y los elementos abrazados se fundirán. Pero esperamos según nos lo tiene prometido, nuevos cielos y nueva tierra, en los que habite la justicia (2 Pe 3, 12-13)" (Santamaría, 2012: 240). Este mensaje apocalíptico claramente contenía exigencias éticas para los judíos y ahora, de acuerdo con Pablo, para los cristianos, para quienes además de tener la primicia de ver la llegada del Mesías participan de la gloria de ser hijos de Dios (Vidal, 1996: 432).

También, la imagen de una mujer en el momento del trabajo de parto (v. 22) es una tradición no sólo de dolor o sufrimiento sino de dichosa proyección, pues a pesar de los gritos y quejidos se espera ver el nacimiento de una nueva vida (Vidal, 1996: 433). La contemplación del nuevo rostro de la criatura; es una experiencia que emociona plenamente y glorifica la existencia; una nueva vida, un nuevo ser empieza a surgir abierto a la esperanza. 
En el mismo sentido, hay otros dos textos en que se ha fijado Jordi Sánchez en su estudio sobre la teología de Pablo: Romanos 1, 18-20; en este texto, Pablo recuerda dos fundamentos teóricos: Dios es el creador del cosmos, Ser que trasciende todo lo creado por medio de su palabra y hay bondad en todas las cosas materiales: "las obras de la creación de Dios son como poemas obras perfectamente elaboradas" (Sánchez, 2007: 60). En Romanos 4, 17; Pablo concibe el poder creador de Dios a partir del fundamento del ser o ser absoluto pues, Dios da la vida a los muertos y llama a la existencia lo que no existe: "Las consecuencias son importantísimas, porque aquella fuerza con que Dios creó el mundo actúa en la resurrección de los muertos, y en la de Cristo, y en nuestra resurrección espiritual, llamada justificación (Rm 4, 24s)" (Sánchez, 2007: 60).

Finalmente, Pablo en la carta a los Romanos no habla de la nueva creación pero sí de la creación en cuanto es la obra de Dios. Dios con su poder misericordioso concede el don de la fe en su Hijo Jesucristo y la fe en Él se confirma en el bautismo (Vidal, 1996: 415); también, símbolo de la muerte al pecado y de un nuevo nacimiento o de una nueva vida.

\section{Conclusión}

Cuando Pablo utilizó los conceptos kaine ktisis traducidos como nueva creación, lo hizo para sintetizar el tema de la salvación realizada por Dios en Jesús. Esta síntesis relaciona teológicamente la historia de Pablo de Tarso con la historia de Jesús de Nazaret.

La teología de Pablo ha sido interpretada en sus cartas, entre ellas: Gálatas, Romanos y 2 Corintios, consultadas en este artículo. El motivo o la causa principal de Pablo de Tarso en estos textos es el Evangelio de Jesucristo. También, se obtiene información fundamental sobre la actividad misionera de Pablo en función de este mismo Evangelio.

Pablo de Tarso demostró poseer una tradición teológica de la religión judía o del pueblo de Israel, basada en la concepción de Dios Creador; tradición heredada en su pueblo por los profetas y los maestros de la Ley. Dios tiene el poder de crear y Dios tiene el poder de volver a crear, es decir de realizar una nueva creación. La idea de la nueva creación se originó en la comprensión por parte de Pablo de la elección para la salvación tanto de los circuncidados como de los no circuncidados. Así, se efectuó el cumplimiento de las promesas de Dios hechas a los antepasados de Israel. Esta es la conclusión en las disputas con los cristianos de Galacia.

Pablo confesó la divinidad de Jesús a partir del título de Mesías o Ungido y la identidad de los cristianos la definió como una pertenencia 
comunitaria y adhesión mística al misterio pascual de Jesús; así afirmó estar en Cristo. Esta es la novedad de la salvación para la comunidad cristiana en Corinto; pues lo antiguo (viejo) equiparado con el pecado ha sido liberado por la fuerza del Espíritu de Santidad que inspira una nueva manera de asumir la existencia reconciliados con Dios y siendo dignos herederos de sus beneficios: caridad, fe, esperanza, vida y equidad.

La condición para alcanzar esta herencia dada por la gracia de Dios es reconocer que los trabajos humanos, no hacen buenos ni justos ni a judíos ni a paganos, sino que la salvación de la corrupción se da por el don del amor de Dios a toda su obra de la creación. Esta es la buena noticia para la comunidad cristiana en Roma.

La teología paulina ayuda a comprender a todos los cristianos cómo puede ser posible la realización y el cumplimiento de las palabras del profeta: "aquel día...alejaré de esta tierra el arco, la espada y la guerra, y los haré reposar en seguro" (Os 2, 20). Es la divina armonía de toda la creación por la nueva creación.

\section{REFERENCIAS}

-Auvray, P. (2001). Creación. En X. León-Dufour, Vocabulario de Teología Bíblica. Barcelona: Herder.

-Guijarro, S. (2011). La primera generación en Judea y Galilea. En R. Aguirre (Ed.), Asi empezó el cristianismo. Navarra: Verbo Divino.

-Barbaglio, G. (2009). Jesús de Nazaret y Pablo de Tarso. Confrontación histórica. Salamanca: Secretariado Trinitario.

-Baena, G. (2011). Fenomenología de la Revelación. Teología de la Biblia y bermenéutica. Navarra: Verbo Divino.

-Becker, J. (1996). Pablo el apóstol de los paganos. Salamanca: Sígueme.

-Bornkamm, G. (1982). Pablo de Tarso. Salamanca: Sígueme.

-Gnilka, J. (1998). Pablo de Tarso. Apóstol y testigo. Barcelona: Herder.

-Köster, H. (1988). Introducción al Nuevo Testamento. Historia, cultura y religión de la época belenística e historia, literatura del cristianismo primitivo. Salamanca: Sígueme.

-Lutero, M. (2003). Comentarios de Martín Lutero. Carta del Apóstol Pablo a los Romanos (E. Sexauer, Trad.). Sevilla: Clie.

-Neirynck, F. (2004). El problema sinóptico. En R. Brown, J. Fitzmayer \& R. Murphy (Eds.), Nuevo Comentario Bíblico San Jerónimo (pp. 3-14). Estella (Navarra): Editorial Verbo Divino.

-Rahner, K. (2008). La gracia como libertad. Barcelona: Herder.

-Rodríguez, A. (2009). Salmos 73-106. Bilbao: Desclée de Brouwer.

-Sánchez, J. (2007). Maestro de los pueblos. Una teología de Pablo, el apóstol. Estella (Navarra): Editorial Verbo Divino.

-Santamaría, X. (2012). Carta a los Romanos. Navarra: Verbo Divino.

-Santos, S. (1976). La conversión de San Pablo. Barcelona: Herder.

-Vidal, S. (1996). Las cartas originales de Pablo. Madrid: Trotta. 
-Vouga, F. (2001). Los primeros pasos del cristianismo. Escritos, protagonistas, debates. Navarra: Verbo Divino.

Sumario: Introducción; 1. Las fuentes que relacionan el mensaje de Jesús de Nazaret y Pablo de Tarso; 2. Pablo, Apóstol del Evangelio; 3. La idea de nueva creación en Gálatas 6,11-16; 4. La idea de nueva creación en 2 Corintios 5,17; 5. El concepto de "creación” en Romanos 8,18-22; Conclusión; Referencias. 